\title{
Vesicularity and Rheology of the Kīlauea 2018 Lava Flows
}

\author{
B. HALVERSON ${ }^{1}$, A. WhitTINGTON ${ }^{1}$, J. HAMMER ${ }^{2}$, \\ R. DeGrafFENRIED ${ }^{2}$, E. LEV ${ }^{3}$, H. DiETTERICH ${ }^{4}$, \\ M. PATRICK ${ }^{5}$, C. PARCHETA ${ }^{5}$, B. CARR ${ }^{5}$, M. ZOELleR ${ }^{5}$, \\ F. TRUSDELL ${ }^{5}$, E. LLEWELLIN ${ }^{6}$
}

${ }^{1}$ University of Texas at San Antonio, One UTSA Circle, San Antonio, TX, 78249, brenna.halverson@utsa.edu, alan.whittington@utsa.edu

${ }^{2}$ University of Hawaii, Manoa, 1680 East-West Road, Honolulu, HI 96822, jhammer@hawaii.edu, rdegraff@hawaii.edu

${ }^{3}$ Columbia University, Lamont-Doherty Earth Observatory 61 Rte.9w, Palisades, NY, einatlev@1deo.columbia.edu

${ }^{4}$ USGS Alaska Volcano Observatory

${ }^{5}$ USGS Hawaiian Volcano Observatory

${ }^{6}$ Durham University Science Labs, Durham DH1 3LE, ed.llewellin@durham.ac.uk

The 2018 Kinlauea lava flows were among the best documented lava flows in history, with extensive groundbased observation and Unmanned Aerial Systems (UAS) overflights. This wealth of real-time data enabled us to select sampling locations along the Fissure 8 flow where overflows, ooze-outs, and breakouts had quenched and preserved the texture of flowing lava.

Preservation of flow textures is especially important in highly vesicular flows, where bubble characteristics largely influence flow behaviour. This was the case with Fissure 8, which erupted lavas with vesicularities of $\sim 70 \%$. We collected 35 samples, comprising a range of emplacements times and distances from the vent. Our samples contain variations in volume fraction, shape, and size distribution of vesicles. Vesicle shapes are sub-equant polygonal, oblate (stretched), spherical networks, and arcuate sets. Some samples preserve a marked difference in vesicularity with depth, while others show alternating vesicle-rich and vesiclepoor bands. This range of vesicle shape and size distributions affects the rheology of the flow. This behavior that can be quantified using the capillary number, $\mathrm{Ca}$, a ratio of shear stresses and surface tension acting upon the bubbles. Large or deformed vesicles result in a high $\mathrm{Ca}$ and lowering of viscosity, while smaller or more spherical vesicles lower the capillary number and increase viscosity.

We will combine real-time video with textural measurements, rheological experiments, and numerical models to better understand the emplacement and hazards of Kîlauea lava flows. 